\title{
Realization of a New Current Mode Second-Order Biquad Using Two Current Follower Transconductance Amplifiers (CFTAs)
}

\author{
Nisha Walde*, Syed Naseem Ahmad \\ Department of Electronics \& Comm. Engineering, Jamia Millia Islamia, New Delhi, India \\ Email: ${ }^{*}$ nisha.walde1@gmail.com, snahmad@jmi.ac.in
}

Received 13 March 2015; accepted 15 May 2015; published 18 May 2015

Copyright (C) 2015 by authors and Scientific Research Publishing Inc.

This work is licensed under the Creative Commons Attribution International License (CC BY). http://creativecommons.org/licenses/by/4.0/

(c) (i) Open Access

\begin{abstract}
A new circuit for realization of universal current-mode filter using current Follower Transconductance Amplifiers (CFTAs) is presented. The proposed circuit realizes current-mode low pass, high pass and band pass filter functions simultaneously with a single current source at the input. The band reject and all pass filters can also be obtained from the proposed circuit without any extra hardware. The proposed circuit employs three passive grounded elements and two CFTAs. Linear electronic control of natural frequency $\omega_{0}$ is available in the proposed circuit. The quality factor can be independently adjusted through grounded resistor. The proposed circuit employs two grounded capacitors and a grounded resistor along with two CFTAs. The grounded resistor can be replaced by an OTA based circuit for linear electronic control of quality factor $Q_{0}$. The circuit exhibits low active and passive sensitivities for $\omega_{0}$ and $Q_{0}$. Simulation results are obtained using PSPICE software which is in conformity with the theoretical findings.
\end{abstract}

\section{Keywords}

Current Follower Transconductance Amplifier (CFTA), Current-Mode Circuit, Biquad Filter, Voltage-Mode Circuit, Current Conveyor (CC)

\section{Introduction}

Current mode circuits are very popular due to some of their advantages over their voltage mode counter parts.

"Corresponding author.

How to cite this paper: Walde, N. and Ahmad, S.N. (2015) Realization of a New Current Mode Second-Order Biquad Using Two Current Follower Transconductance Amplifiers (CFTAs). Circuits and Systems, 6, 113-120. 
They are very suitable for high frequency, low voltage and low power applications in portable equipments such as mobile phones, aviation industry, water quality monitoring equipments, medical instrumentation and in satellite communication equipments. Current mode approach in analog processing blocks offers high slew rates, low node impedances, greater linearity, wider bandwidth and sometimes electronic tunability compared with voltage mode circuits. There have been steady and gradual interests to find new schemes for analog building blocks which may serve as an excellent current mode device. Some of the popular and off-the-shelf items have been Current Feedback Amplifiers (AD844) [1], Current Conveyors [2], Operational Transconductance Amplifiers (CA 3080) [3] etc., which have been used for decades as excellent current mode devices. Recently introduced current mode building blocks are Current Differencing Transconductance Amplifiers (CDTAs) [4]-[7], and Current Follower Transconductance Amplifiers (CFTAs) [8]-[23] which provide simple design facility with ample numbers of choices for output current ports for excellent current mode signal processing. CFTA in addition to possessing single current input compared with CDTA also exhibits excellent current mode characteristics along with electronic control of parameters of interest and is therefore attracting the attention of analog circuit designers. CFTA is extensively used in the realization of signal processing as well as signal generation in current mode circuits [7]-[23]. In this paper, a new circuit using two CFTAs and two grounded capacitors along with a grounded resistor is presented. The proposed circuit realizes basic current mode filter functions such as low pass (LP), band pass (BP), and high pass (HP) for a single input current source. Also, band reject (BR) and all-pass (AP) filter functions can be realized by proper combinations of current responses. Various papers are published on different applications of CFTAs such as current-mode (CM) or voltage-mode (VM) universal filters, oscillators, amplifiers, etc. [7]-[23]. In this paper, a new current-mode second-order CFTA biquad filter is presented which uses two active elements and three passive grounded elements. The main attractive feature of this circuit is the facility of linear control of pole frequency $\omega_{0}$ and quality factor $Q_{0}$. While pole frequency can be changed electronically through $g_{m}$, the quality factor $Q_{0}$ can be adjusted independently through grounded resistor. The grounded resistor can further be realized through an additional transconductance amplifier making this control again an electronic one. The simulation results are obtained using PSPICE software. Simulation results validate the theoretical findings.

\section{Proposed circuit Realization of Current Follower Transconductance Amplifier (CFTA)}

The Current Follower Transconductance Amplifier (CFTA) [6], whose schematic symbol and behavioral model are shown in Figure 1(a)-(b), consists of an input current follower that transfers the input current to the $z$ terminal and an output transconductance amplifier stage, which is used to convert the voltage at the $z$-terminal into output currents. Relations between the individual terminals of CFTA can be described by the following hybrid matrix:

$$
\left[\begin{array}{c}
v_{f} \\
i_{z} \\
i_{x+} \\
i_{x-}
\end{array}\right]=\left[\begin{array}{cccc}
0 & 0 & 0 & 0 \\
1 & 0 & 0 & 0 \\
0 & g_{m} & 0 & 0 \\
0 & -g_{m} & 0 & 0
\end{array}\right]\left[\begin{array}{c}
i_{f} \\
v_{z} \\
v_{x+} \\
v_{x-}
\end{array}\right]
$$

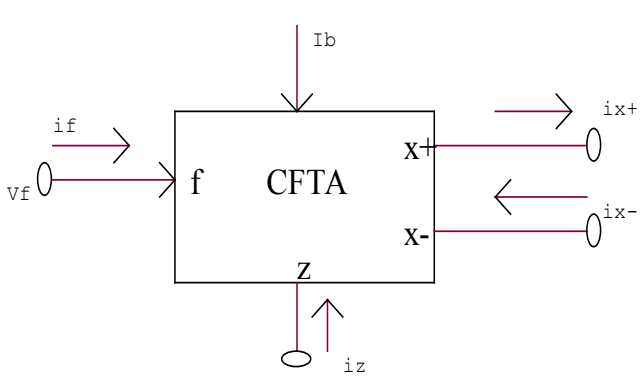

(a)

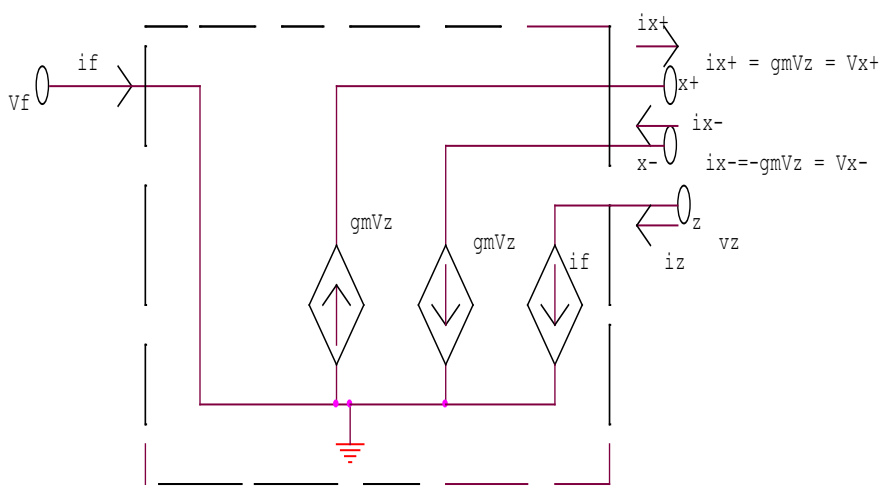

(b)

Figure 1. (a) The CDTA schematic symbol; (b) Behavioral model of CFTA. 
Assuming the standard notations, the terminals defining relations of this device can be characterized by the following set of equations

$$
v_{f}=0, i_{z}=i_{f} \text { and } i_{x+}=g_{m} v_{z}=g_{m} z_{z} i_{z}, i_{x-}=-g_{m} v_{z}
$$

where $g_{m}$ is transconductance gain of the CFTA which is directly proportional to the external bias current $I_{B}$, which is given by Equation (3)

$$
g_{m}=\frac{I_{B}}{2 V_{T}}
$$

where the $V_{T}$ is the thermal equivalent voltage $\left(=26 \mathrm{mV}\right.$ at $\left.27^{\circ} \mathrm{C}\right)$ and $I_{B}$ is the control bias current adjusting the transconductance $g_{m}$ of the CFTA. The operation of the CFTA will be dependent on temperature variations. $z_{z}$ is external impedance connected to the z-terminal.

The proposed current mode biquad filter is shown in Figure 2. It consists of two CFTAs, one grounded resistor and two grounded capacitors. The internal construction of CFTA used for simulation is shown in Figure 3.

A routine analysis of the proposed circuit as shown in Figure 2 yields the following current transfer functions.

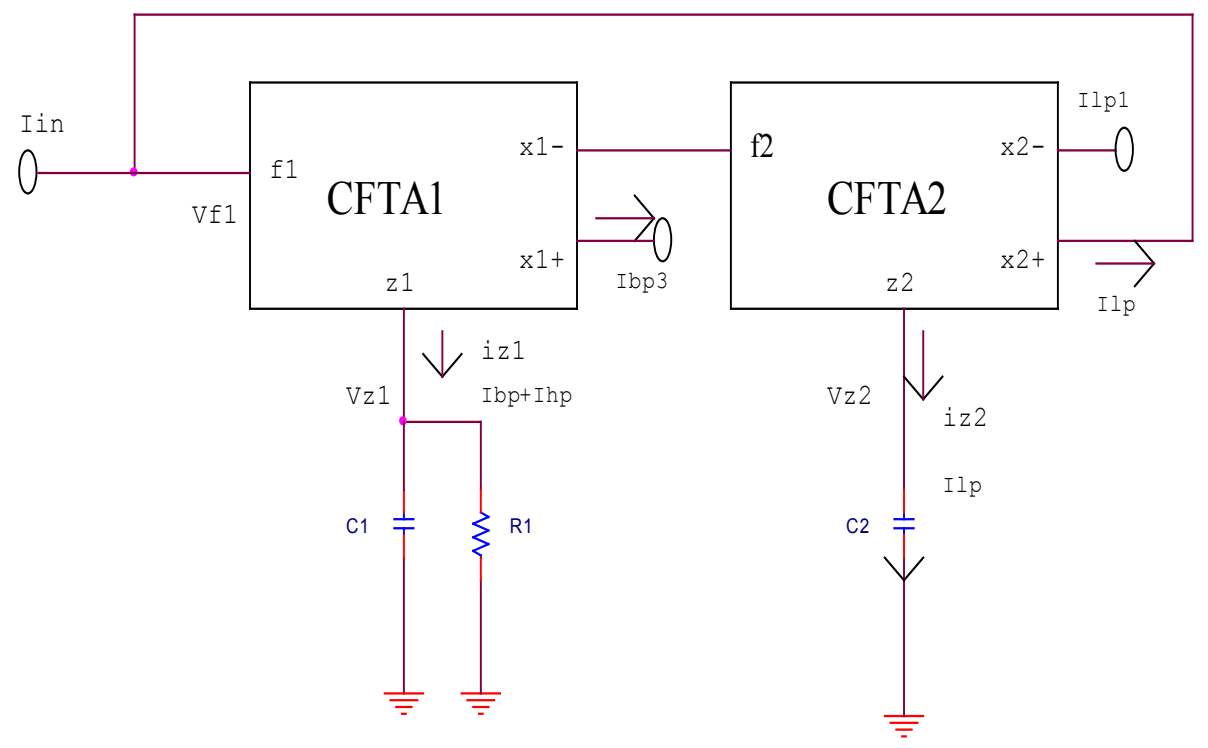

Figure 2. Proposed current mode second-order biquad filter using CFTAs.

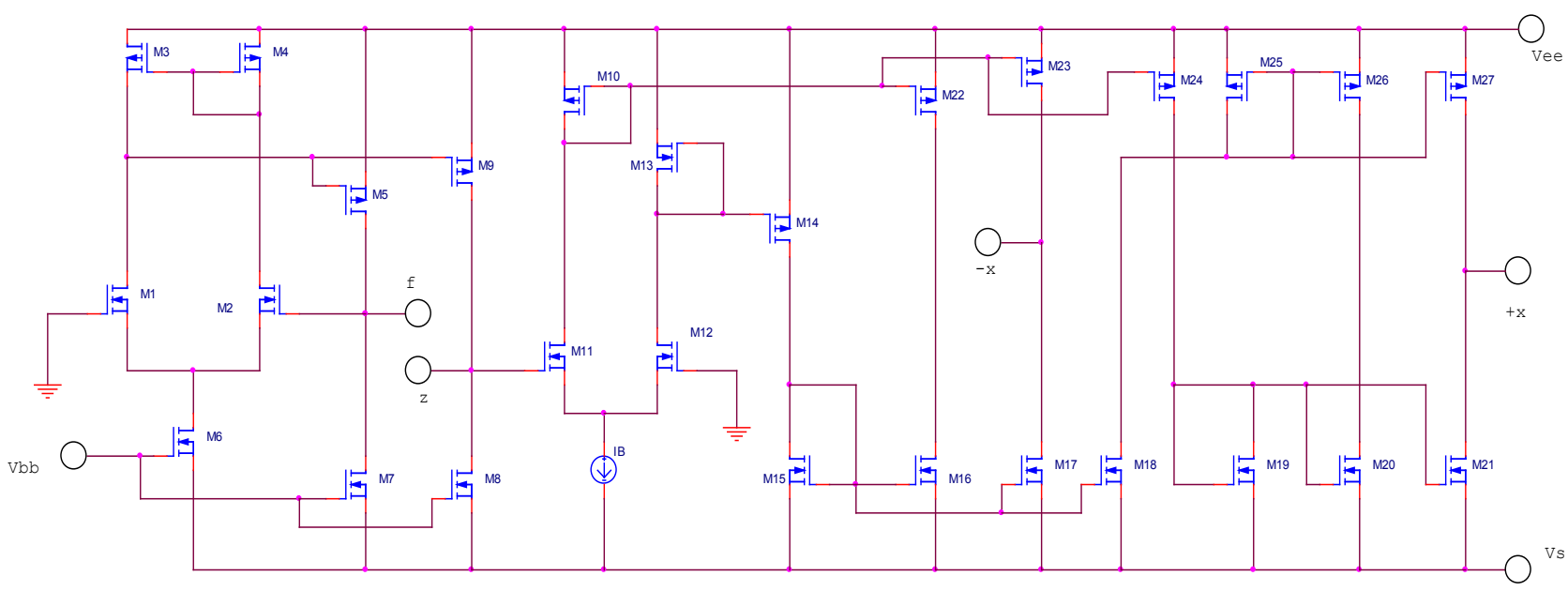

Figure 3. A CMOS implementation of CFTA used for simulations. 


$$
\begin{gathered}
\frac{I_{h p}}{I_{i n}}=\frac{s^{2}}{D(s)} \\
\frac{I_{b p}}{I_{i n}}=\frac{-s\left(\frac{G_{1}}{C_{1}}\right)}{D(s)} \\
\frac{I_{l p}}{I_{i n}}=\frac{\left(\frac{g_{m} g_{m 2}}{C_{1} C_{2}}\right)}{D(s)}
\end{gathered}
$$

Adding the output current reponses $I_{l p}$ and $I_{h p}$, one obtains

$$
\frac{I_{b r}}{I_{i n}}=\frac{s^{2}+\left(\frac{g_{m 1} g_{m 2}}{C_{1} C_{2}}\right)}{D(s)}
$$

whereas for current-mode all-pass filter response

$$
\frac{I_{a p}}{I_{i n}}=\frac{s^{2}-s\left(\frac{G_{1}}{C_{1}}\right)+\left(\frac{g_{m 1} g_{m 2}}{C_{1} C_{2}}\right)}{D(s)}
$$

where $D(s)$ is given by

$$
D(s)=s^{2}+s\left(\frac{G_{1}}{C_{1}}\right)+\left(\frac{g_{m 1} g_{m 2}}{C_{1} C_{2}}\right)
$$

From (4)-(9), the pole frequency $\omega_{0}$ and quality factor $Q_{0}$ are given as

$$
\begin{gathered}
\omega_{0}=\sqrt{\frac{g_{m 1} g_{m 2}}{C_{1} C_{2}}} \\
Q_{0}=\frac{1}{G_{1}} \sqrt{\frac{g_{m 1} g_{m 2} C_{1}}{C_{2}}}
\end{gathered}
$$

For $g_{m 1}=g_{m 2}=g_{m}$ and $C_{1}=C_{2}=C$ Equations (10) and (11) become

$$
\omega_{0}=\frac{g_{m}}{C}
$$

and

$$
Q_{0}=\frac{g_{m}}{G_{1}}
$$

Equations (12) and (13) show that $\omega_{0}$ can be linearly and electronically varied through $g_{m}$. Whereas quality factor $Q_{0}$ can be linearly changed through grounded resistor $R_{1}$ independent of $\omega_{0}$.

\section{Tracking Errors}

There are Current Tracking Errors of the proposed circuit. The characteristic equations of CFTA are

$$
v_{f}=0, i_{z}=\alpha i_{f}, i_{x+}=g_{m} v_{z}, i_{x-}=-g_{m} v_{z}
$$

where $\alpha=1-\epsilon_{i}$ where $\epsilon_{i}$ denotes the current tracking error of the current follower from the terminal $f$ into the terminal-z $\left(\| \epsilon_{i} \ll 1\right)$. from the non-ideal properties of CFTAs, the characteristic equation of the proposed 
circuit according to Figure 2 is

$$
D(s)=s^{2} c_{1} c_{2}+\alpha_{2} s c_{2} G_{1}+\alpha_{1} \alpha_{2} g_{m 1} g_{m 2}=0
$$

It is thus, seen that the proposed circuit is capable of realizing all the five basic functions, without requiring any component-matching or realization conditions. From (4)-(9), the various filter parameters are given by

$$
\begin{aligned}
& \omega_{0}=\sqrt{\frac{\alpha_{1} \alpha_{2} g_{m 1} g_{m 2}}{C_{1} C_{2}}} \\
& Q_{0}=\frac{1}{G_{1}} \sqrt{\frac{g_{m 1} g_{m 2} C_{1}}{C_{2}}}
\end{aligned}
$$

\section{Sensitivity Analysis}

The effect of changes in active and passive element values is determined by evaluating sensitivity coefficients which are found to be

$$
\begin{gathered}
S_{\alpha_{1} \alpha_{2}}^{\omega_{0}}=S_{g_{m 1}}^{\omega_{0}}=S_{g_{m 2}}^{\omega_{0}}=-S_{c_{1}}^{\omega_{0}}=-S_{c_{2}}^{\omega_{0}}=\frac{1}{2} \\
S_{G_{1}}^{Q_{0}}=-1 \\
S_{g_{m 1}}^{Q_{0}}=S_{g_{m 2}}^{Q_{0}}=S_{c_{1}}^{Q_{0}}=S_{\alpha_{1}}^{Q_{0}}=S_{\alpha_{2}}^{Q_{0}}=-S_{C_{2}}^{Q_{0}}=\frac{1}{2}
\end{gathered}
$$

From (12)-(20), it is clear that all the sensitivities of the various parameters of the filters realized from the proposed configuration are very low.

\section{Simulation Results}

The performance of the proposed circuit in Figure 2 has been verified by PSPICE simulation results. The PMOS and NMOS transistors have been simulated by respectively using the parameters of a $0.25 \mu \mathrm{m}$ TSMC CMOS technology [9] as shown in Table 1. The aspect ratios of PMOS and NMOS transistors are indicated in Table 2. The circuit was biased with $\pm 1.5 \mathrm{~V}$ power supply voltage, $V_{B B}=-0.55 \mathrm{~V}, I_{B 1}=I_{B 2}=80 \mu \mathrm{A}$. The values of the capacitors and resistor were chosen as: $C_{1}=C_{2}=1 \mathrm{n} F, R_{1}=0.5 \mathrm{k} \Omega$. In Figure 4(a), simulated results of proposed LP, HP, BP, BR filters are shown using PSPICE 16.3 which shows the validity of design equations of filter shown in Equations (10) and (11). Pole frequency was found to be $f_{0}=245 \mathrm{kHz}$ and quality factor $Q_{0}=0.7$ which are very close to theoretical values. In Figure 4(b), phase response of current mode all-pass filter is shown. In Figure 4(c), simulation results are shown for the pole frequency $f_{0}=245 \mathrm{kHz}$ and quality factor $Q_{0}$ which varies from 0.7 to 3 . The results show independent control of $Q_{0}$. Similarly, in Figure 4(d) for the quality

\begin{tabular}{|c|c|}
\hline NMOS & $\begin{array}{l}\text { NMOS }(\text { LEVEL }=3 \text { TOX }=5.7 \mathrm{E}-9 \mathrm{NSUB}=1 \mathrm{E} 17+\mathrm{GAMMA}=0.4317311 \mathrm{PHI}=0.7 \mathrm{VTO}=0.4238252 \mathrm{DELTA}=0 \\
\mathrm{UO}=425.6466519 \mathrm{ETA}=0 \text { THETA }=0.1754054 \mathrm{KP}=2.501048 \mathrm{E}-4 \mathrm{VMAX}=8.287851 \mathrm{E} 4 \mathrm{KAPPA}=0.1686779 \\
\mathrm{RSH}=4.062439 \mathrm{E}-3 \mathrm{NFS}=1 \mathrm{E} 12 \mathrm{TPG}=1 \mathrm{XJ}=3 \mathrm{E}-7 \mathrm{LD}=3.162278 \mathrm{E}-11 \mathrm{WD}=1.232881 \mathrm{E}-8 \mathrm{CGDO}=6.2 \mathrm{E}-10 \\
\mathrm{CGSO}=6.2 \mathrm{E}-10 \mathrm{CGBO}=1 \mathrm{E}-10 \mathrm{CJ}=1.81211 \mathrm{E}-3 \mathrm{~PB}=0.5 \mathrm{MJ}=0.3282553 \mathrm{CJSW}=5.341337 \mathrm{E}-10+\mathrm{MJSW}=0.5)\end{array}$ \\
\hline PMOS & $\begin{array}{c}(\mathrm{LEVEL}=3 \mathrm{TOX}=5.7 \mathrm{E}-9 \mathrm{NSUB}=1 \mathrm{E} 17 \mathrm{GAMMA}=0.6348369 \mathrm{PHI}=0.7 \mathrm{VTO}=-0.5536085 \mathrm{DELTA}=0 \mathrm{UO}=250 \\
\mathrm{ETA}=0 \text { THETA }=0.1573195 \mathrm{KP}=5.194153 \mathrm{E}-5 \mathrm{VMAX}=2.295325 \mathrm{E} 5 \mathrm{KAPPA}=0.7448494 \mathrm{RSH}=30.0776952 \\
\mathrm{NFS}=1 \mathrm{E} 12 \mathrm{TPG}=-1 \mathrm{XJ}=2 \mathrm{E}-7 \mathrm{LD}=9.968346 \mathrm{E}-13 \mathrm{WD}=5.475113 \mathrm{E}-10 \mathrm{CGDO}=6.66 \mathrm{E}-10 \mathrm{CGSO}=6.66 \mathrm{E}-10 \\
\mathrm{CGBO}=1 \mathrm{E}-10 \mathrm{CJ}=1.893569 \mathrm{E}-3 \mathrm{~PB}=0.9906013 \mathrm{MJ}=0.4664287 \mathrm{CJSW}=3.625544 \mathrm{E}-10 \mathrm{MJSW}=0.5)\end{array}$ \\
\hline
\end{tabular}
factor $Q_{0}=0.7$, pole frequency $f_{0}$ is varied from $245.6 \mathrm{kHz}$ to $245 \mathrm{MHz}$. However it is seen that $H_{0}$ in this case is slightly changing with frequency which may be the effect of output parasitic capacitance of CFTA or due to tracking errors between $I_{f}$ and $I_{z}$. Hence, from the PSPICE simulation results it is proved that the practical results nearly match to the theoretical results.

\section{Table 1. The SPICE model parameters of MOS transistors for level 3, $0.25 \mu \mathrm{m}$ CMOS process from TSMC.}




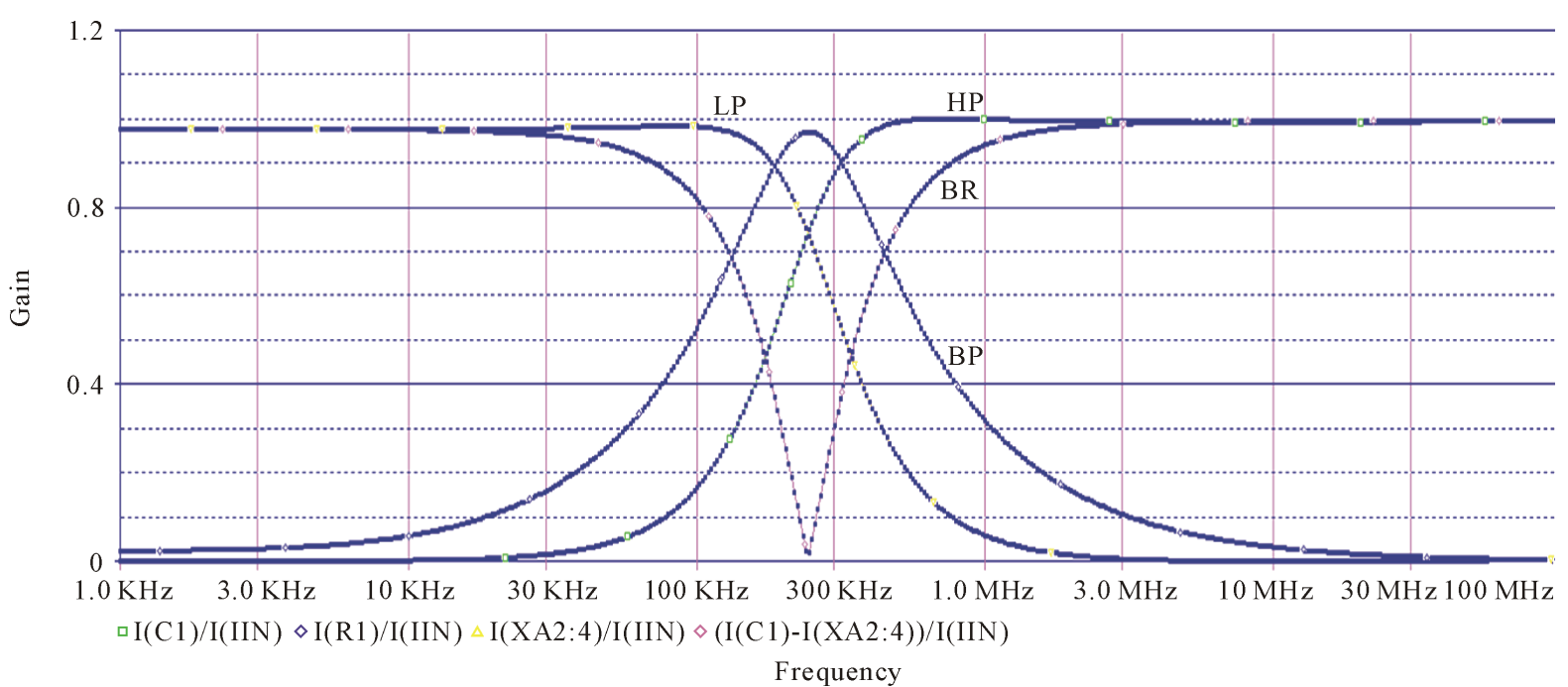

(a)

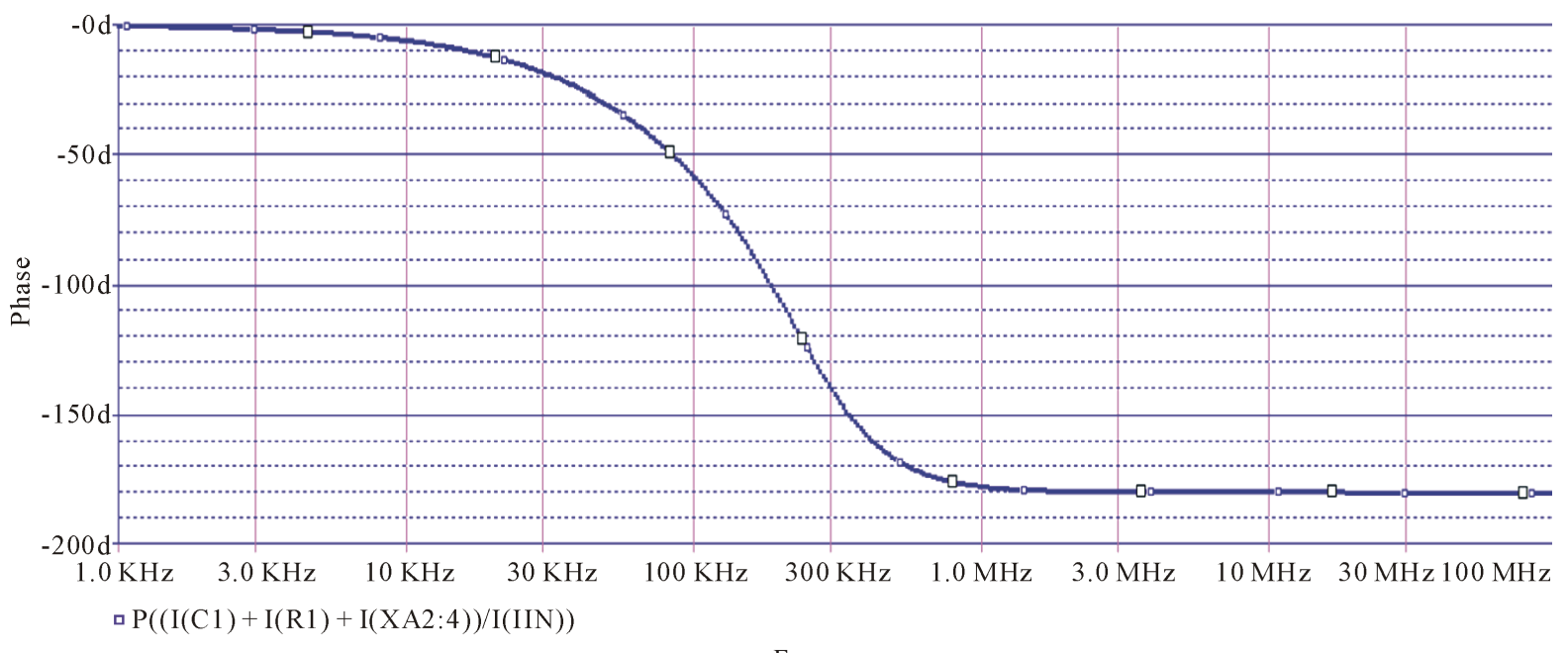

Frequency

(b)

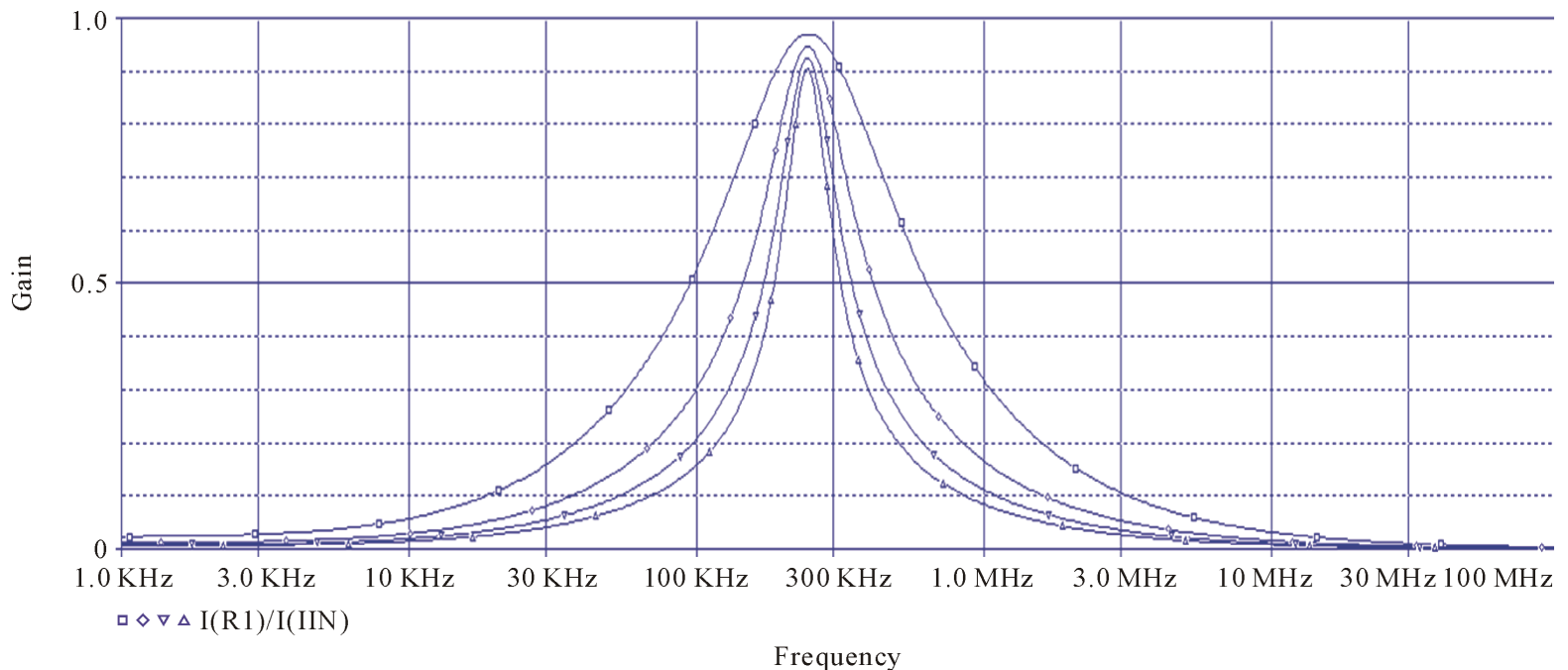

(c) 


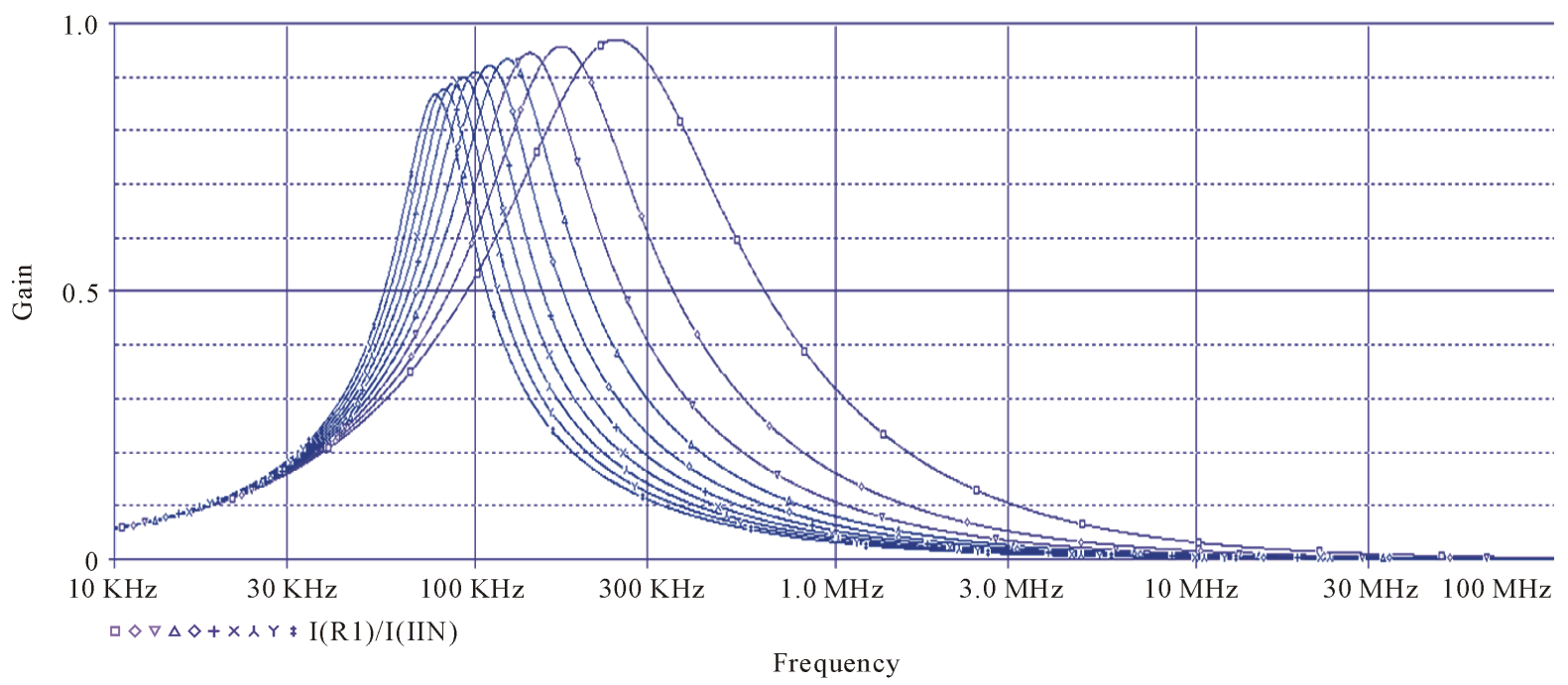

(d)

Figure 4. (a) Simulated frequency response of LP, HP, BP, and BR proposed CFTA current-mode second order biquad filter according to Figure 2; (b) Phase response of all pass proposed biquad filter; (c) Simulated frequency responses of the BP filter when $Q_{0}$ is varied for $f_{0}=245 \mathrm{khz}$; (d) BP filter with different $f_{0}$ (keeping $Q_{0}$ approximately constant).

Table 2. Dimensions of the transistors.

\begin{tabular}{ccc}
\hline Transistor & $W$ (um) & $L$ (um) \\
\hline M1-M2, M19-M20 & 1 & 0.25 \\
M3-M5, M9-M10, M13, M22-M27 & 5 & 0.25 \\
M6-M8, M15-M21 & 3 & 0.25 \\
M11-M12 & 25 & 0.25 \\
M14 & 4.5 & 0.25 \\
\hline
\end{tabular}

\section{Conclusion}

In this paper, a new current-mode second-order biquad filter using CFTAs (Current Follower Tranconductance Amplifier) is presented. The circuit realizes all types of filter functions, i.e. LPF, BPF, HPF, and BRF simultaneously for a single current input. It consists of two CFTAs, one grounded resistor and two grounded capacitors. Hence, the low numbers of active and passive elements are used. The circuit has the features of low voltage supply, and large bandwidth. It has low-input and high-output impedances and also is convenient for electronic controllability through transconductance gain $g_{m}$ of CFTAs, so it can be used in battery-powered or portable electronic equipments. The only apparent drawback is the use of a grounded resistor. However, grounded resistor can be simulated with additional transconductor and its value can be controlled through $g_{m 3}$. Hence, electronic control of quality factor is possible.

\section{References}

[1] Toumazou, C., Lidgey, F.J. and Haigh, D.G., Eds. (1990) Analogue IC Design: The current mode Approach. Peter Peregrinus Ltd., London.

[2] Sedra, A. and Smith, K.C. (1970) A Second-Generation Current Conveyor and Its Applications. IEEE Transactions on Circuit Theory, 17, 132-134. http://dx.doi.org/10.1109/TCT.1970.1083067

[3] Geiger, R.L. and Sanchez-Sinencio, E. (1985) Active Filter Design Using Operational Transconductance Amplifiers: A Tutorial. IEEE Circuits and Devices Magazine, 1, 20-32.

[4] Biolek, D. (2003) CDTA—Building Block for Current-Mode Analog Signal Processing. Proceedings of the European 
Conference on Circuit Theory and Design (ECCTD '03), Krakow, 397-400.

[5] Uygur, A., Kuntman, H. and Zeki, A. (2005) Multi-Input Multi-Output CDTA-Based KHN Filter. Proc. Int. Conf. Electrical and Electronics, Bursa.

[6] Biolek, D., Senani, R., Biolkova, V. and Kolka, Z. (2008) Active Elements for Analog Signal Processing: Classification, Review, and New Proposals. Radioengineering, 17, 15-32.

[7] Tangsrirat, W. (2009) Cascadable Current-Controlled Current-Mode Universal Filters Using CDTAs and Grounded Capacitors. Journal of Active and Passive Electronic Devices, 4, 135-145.

[8] Herencsar, N., Koton, J., Vrba, K. and Misurec, J. (2009) A Novel Current-Mode SIMO Type Universal Filter Using CFTAs. Contemporary Engineering Sciences, 2, 59-66.

[9] Prommee, P., Angkeaw, K., Somdunyakanok, M. and Dejhan, K. (2009) CMOS-Based near Zero-Offset Multiple Inputs Max-Min Circuits and Its Applications. Analog Integrated Circuits and Signal Processing, 61, 93-105.

[10] Tangsrirat, W. (2010) Novel Current-Mode and Voltage-Mode Universal Biquad Filters Using Single CFTA. Indian Journal of Engineering and Materials Sciences, 17, 99-104.

[11] Herencsar, N., Koton, J. and Vrba, K. (2010) Realization of Current-Mode KHN-Equivalent Biquad Using Current Follower Transconductance Amplifiers (CFTAs). IEICE Transactions on Fundamentals of Electronics, Communications and Computer Sciences A, E93-A, 1816-1819. http://dx.doi.org/10.1587/transfun.E93.A.1816

[12] Tangsrirat, W. (2011) Single-Input Three-Output Electronically Tunable Universal Current-Mode Filter Using Current Follower Transconductance Amplifiers. International Journal of Electronics and Communications, 65, 783-787.

[13] Herencsar, N., Koton, J., Vrba, K. and Lattenberg, I. (2011) Current Follower Transconductance Amplifier (CFTA) A Useful Building Block for Analog Signal Processing. Journal of Active and Passive Electronic Devices, 6, $217-229$.

[14] Satansup, J. and Tangsrirat, W. (2011) Realization of Current-Mode KHN-Equivalent Biquad Filter Using ZC-CFTAs and Grounded Capacitors. Indian Journal of Pure and Applied Physics, 49, 841-846.

[15] Iamarejin, A., Maneewan, S., Suwanjan, P. and Jaikla, W. (2013) Current-Mode Variable Current Gain First-Order Allpass Filter Employing CFTAs. Przeglad Elektrotechniczny, 89, 238-241.

[16] Satansup, J., Pukkalanun, T. and Tangsrirat, W. (2011) Current-Mode KHN Biquad Filter Using Modified CFTAs and Grounded Capacitors. Proceedings of the International Multi Conference of Engineers and Computer Scientists, Hong Kong, 16-18 March 2011.

[17] Satansup, J. and Tansrirat, W. (2011) Realization of Current-Mode KHN-Equivalent Using ZC-CFTAs and Grounded Capacitors. Indian Journal of Pure \& Applied Physics, 49, 841-846.

[18] Singh, B., Singh, A.K. and Senani, R. (2012) New Universal Current-Mode Biquad Using Only Three ZC-CFTAs. Radio Engineering, 21, 273-280.

[19] Wisut, S.L. and Siripruchyanun, M. (2012) A Current-Mode Multifunction Biquadratic Filter Using CFTAs. The Journal of KMUTNB, 22, 479-485. http://dx.doi.org/10.14416/j.kmutnb.2012.03.002

[20] Singh, S.V., Tomar, R.S. and Chauhan, D.S. (2014) ZC-CFTA-Based Trans-Impedance-Mode Universal Biquad Filter with Electronic Tuning. IEEE International Conference on Signal Processing and Integrated Networks (SPIN), Noida, 20-21 February 2014, 543-548.

[21] Suwanjan, P. and Jaikla, W. (2012) CFTA Based MISO Current-Mode Biquad Filter. Proceedings of the Recent Researches in Circuits, Systems, Multimedia and Automatic Control, Rovaniemi, 18-20 April 2012, 93-97.

[22] Tangsrirat, W. (2014) SFG Synthesis of General High-Order All-Pass and All-Pole Current Transfer Functions Using CFTAs. The Scientific World Journal, 2014, 1-5.

[23] Herencsar, N., Koton, J., Vrba, K. and Lahiri, A. (2010) Current-Controlled CFTA-Based Current-Mode SITO Universal Filter and Quadrature Oscillator. Proceedings of the 2010 International Conference on Applied Electronics $(A E)$, Pilsen, 8-9 September 2010, 1-4. 